\title{
Modelling and Simulation of Skid Prediction in a Passenger Car
}

\author{
Shivram M, Srinivaas A
}

\begin{abstract}
The vehicle handling is defined as the responsiveness of a vehicle to the driver input. The driver and vehicle is a closed loop system where the driver observes the direction or position of the vehicle in order to correct his input to achieve the desired motion. It is required for the driver to safely ride the vehicle particularly during cornering, acceleration and braking in order to avoid skidding. The skid occurring in a vehicle is a condition in automobile handling where one or more tyres slip relative to the road and the overall vehicle handling gets affected. Tire slip and related slip angle describe the performance of an individual tire. The cornering behaviour of a vehicle is one of the important modes in handling. In this project, a mathematical model is build using MATLAB-SIMULINK for a passenger car undergoing cornering. The steer angles for various speeds and radius of turns are determined and the results are displayed in the form of graphs. An app is designed using the $M A T L A B$ app designer which predicts the type of skid- under steer, over steer or neutral steer while the vehicle is undergoing cornering. This system is then simulated in the real time environment with the help of IPG Carmaker and driving scenario designer app in MATLAB and the corresponding results are noted.
\end{abstract}

Keywords - skid, vehicle handling, MATLAB-SIMULINK, IPG Carmaker, steer angle, cornering, driving scenario designer.

\section{INTRODUCTION}

The automobile industry in India is one of the fastest growing sectors. This is because of the increase in the number of automobile users in the country. So the number of automobile companies has increased to a great extent and very high competition exists between these companies. In order to sustain their products in the market many new model vehicles along with innovative designs and latest technologies are being introduced. The driver and vehicle is a closed loop system where the driver observes the direction of the vehicle and corrects his input in order to maintain the lane discipline and turn to the desired direction. It is required for the driver to safely ride the vehicle particularly during cornering, acceleration and braking in order to avoid skidding.

An automobile skid is a very important factor affecting the vehicle handling. A skid occurs when there is a slip occurring in the tyres of the vehicle relative to the road. The skid is the condition where the vehicle is moving but the tyres are not rotating or the vehicle is stationary and the tyres are rotating. The surface conditions of the road also play a major role in skidding. Some of the roads surfaces at which skidding of the vehicle occur frequently are sand,

Revised Manuscript Received on July 10, 2019.

Shivram M, Department of Mechanical Engineering, Amrita School of Engineering, Amrita Vishwa Vidyapeetham, Coimbatore, India. (E-mail: mshivram100@gmail.com)

Srinivaas A, Department of Mechanical Engineering, Amrita School of Engineering, Amrita Vishwa Vidyapeetham, Coimbatore, India. snow, ice, oil, etc where the coefficient of friction of the tyres reduces. The major types of skid in automobiles are:

- Fishtailing

- Spin out

- Burn out

- Under steer

- Over steer

- Skidding during braking

\section{STEADY STATE CORNERING}

The cornering is the term which refers to the turning the vehicle along a curved path with the help of steering wheel. Proper utilisation of the steering wheel can reduce a large number of accidents from taking place.

\subsection{Low speed cornering}

At low speeds, the vehicle tyres do not develop lateral force and roll without slip angle so that the vehicle should negotiate a turn. Here, the centre of turn of the vehicle should lie on the rear axle's projection as shown in the figure. Also, the perpendicular from each of the front wheels must pass through the centre of turn.

Steer angle of the outer wheel:

$$
\delta_{0}=\mathrm{L} /(\mathrm{R}+\mathrm{t} / 2)
$$

Steer angle of the inner wheel:

$$
\delta_{\mathrm{i}}=\mathrm{L} /(\mathrm{R}-\mathrm{t} / 2)
$$

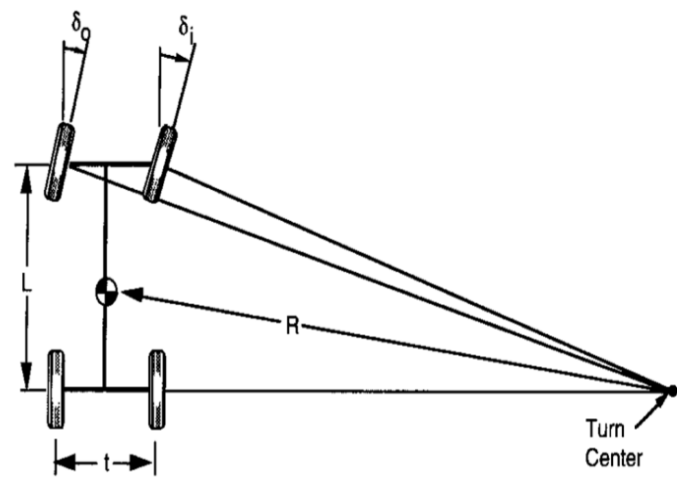

Fig 2.1. Low speed turning

Where

$\mathrm{L}=$ wheelbase of the vehicle $(\mathrm{m})$

$\mathrm{R}=$ radius of turn $(\mathrm{m})$

$\mathrm{t}=$ trackwidth $(\mathrm{m})$ 


\section{MODELLING AND SIMULATION OF SKID PREDICTION IN A PASSENGER CAR}

\subsection{High speed cornering}

At high speeds, the vehicle develops lateral acceleration in them. In order to counteract this lateral acceleration lateral forces are developed in the tires and slip angles also gets developed at each wheel. The angle between the direction of travel and direction of heading of the vehicle is called the slip angle, $\alpha$. When the camber angle becomes zero in a vehicle, a lateral force, $F_{\mathrm{y}}$ deveolps. For the given tire load, the cornering force gradually increases with the slip angle. At low slip angles the cornering force is given by

$$
F_{\mathrm{y}}=C_{\alpha} \alpha
$$

The proportionality constant $C_{\alpha}$ is called the cornering stiffness which is referred to as the ability of a tyre to resist the deformation in shape while the cornering in a vehicle.

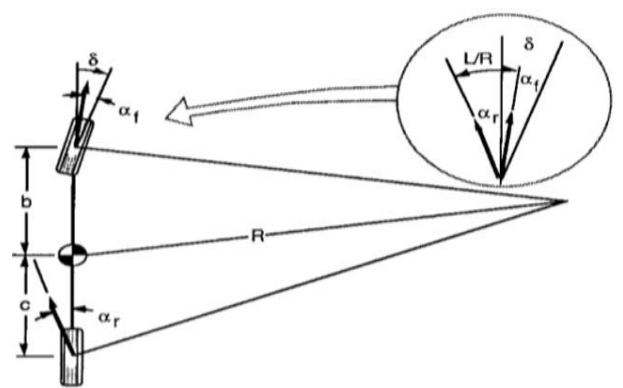

Fig 2.2. High speed cornering

The steer angle(deg) at the front wheels is given by

$$
\delta=57.3 \mathrm{~L} / \mathrm{R}+\left(\left(\mathrm{W}_{\mathrm{f}} / \mathrm{C}_{\alpha \mathrm{f}}\right)-\left(\mathrm{W}_{\mathrm{r}} / \mathrm{C}_{\alpha \mathrm{r}}\right)\right) V^{2} / \mathrm{gR}
$$

Where

$\mathrm{L}=$ wheelbase $(\mathrm{m})$

$\mathrm{R}=$ radius of $\operatorname{turn}(\mathrm{m})$

$\mathrm{V}=$ forward $\operatorname{speed}(\mathrm{m} / \mathrm{s})$

$\mathrm{g}=$ gravitational acceleration $\left(\mathrm{m} / \mathrm{s}^{2}\right)$

$\mathrm{W}_{\mathrm{f}}=$ load on the front axle $(\mathrm{kg})$

$\mathrm{W}_{\mathrm{r}}=$ load on the rear axle $(\mathrm{kg})$

$\mathrm{C}_{\alpha \mathrm{f}}=$ cornering stiffness of front tyres $(\mathrm{kg} / \mathrm{deg})$

$\mathrm{C}_{\mathrm{ar}}=$ cornering stiffness of rear tyres $(\mathrm{kg} / \mathrm{deg})$

\section{MODELLING OF PASSENGER CAR}

\subsection{Assumptions}

- Wheelbase $=2.5 \mathrm{~m}$

- Track width $=1.7 \mathrm{~m}$

- Kerb weight $=1200 \mathrm{~kg}$

- The centre of gravity is at $1 / 3^{\text {rd }}$ length of the wheelbase from the front end.

\subsection{Distribution of forces acting on the car}

Weight distribution of a vehicle can be referred to the amount of the total vehicle's weight imposed on the ground at axles or on individual wheel. The car's weight must be distributed on the axles of the vehicle to comply with the axle rating of chassis manufacturer and weight laws.

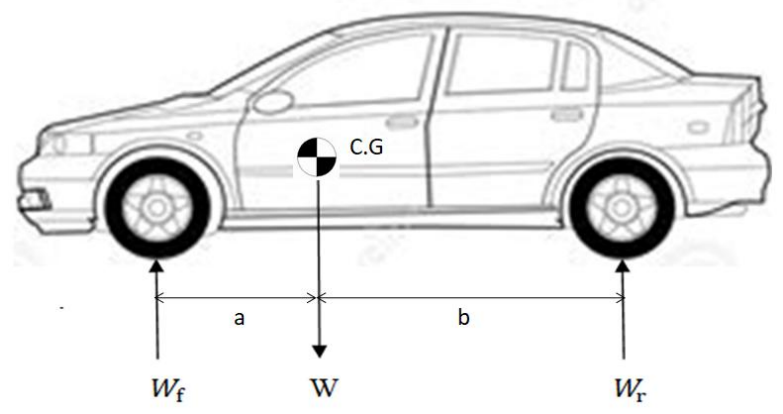

Fig 3.1. Weight distribution of a car

The above diagram indicates the various loads acting on a car which is stationary and parked on a level road .

$\mathrm{W}_{\mathrm{f}}=$ load on the front axle $(\mathrm{kg})$

$\mathrm{W}_{\mathrm{r}}=$ load on the rear axle $(\mathrm{kg})$

$\mathrm{W}=$ total weight of the $\mathrm{car}(\mathrm{kg})$

$\mathrm{a}=$ distance of the front axle from C.G (m)

$\mathrm{b}=$ distance of the front axle from C.G (m)

$\mathrm{L}=\mathrm{a}+\mathrm{b}$

$\mathrm{W}=\mathrm{W}_{\mathrm{f}}+\mathrm{W}_{\mathrm{r}}$

$\mathrm{K}=\left(\mathrm{W}_{\mathrm{f}} / \mathrm{C}_{\alpha \mathrm{f}}\right)-\left(\mathrm{W}_{\mathrm{r}} / \mathrm{C}_{\alpha \mathrm{r}}\right)$

Taking moment about front axle, $\mathrm{W}_{\mathrm{r}}=(\mathrm{a} * \mathrm{~W}) / \mathrm{L}$

Taking moment about rear axle, $\mathrm{W}_{\mathrm{f}}=(\mathrm{b} * \mathrm{~W}) / \mathrm{L}$

\section{SIMULATION OF THE PASSENGER CAR}

\subsection{Various possibilities of cornering}

- Neutral steer - $\mathrm{W}_{\mathrm{f}} / \mathrm{C}_{\alpha \mathrm{f}}=\mathrm{W}_{\mathrm{r}} / \mathrm{C}_{\alpha \mathrm{r}} ; \mathrm{K}=0 ; \alpha_{\mathrm{f}}=\alpha_{\mathrm{r}}$

- Under steer - $\mathrm{W}_{\mathrm{f}} / \mathrm{C}_{\alpha \mathrm{f}}>\mathrm{W}_{\mathrm{r}} / \mathrm{C}_{\alpha \mathrm{r}} ; \mathrm{K}>0 ; \alpha_{\mathrm{f}}>\alpha_{\mathrm{r}}$

- Over steer - $\mathrm{W}_{\mathrm{f}} / \mathrm{C}_{\alpha \mathrm{f}}<\mathrm{W}_{\mathrm{r}} / \mathrm{C}_{\alpha \mathrm{r}} ; \mathrm{K}<0 ; \alpha_{\mathrm{f}}<\alpha_{\mathrm{r}}$

The slip angles of the front and the rear wheels is given by

$$
\begin{aligned}
& \alpha_{\mathrm{f}}=\mathrm{W}_{\mathrm{f}} V^{2} / \mathrm{C}_{\alpha \mathrm{f}} \mathrm{gR} \text { for the front wheels } \\
& \alpha_{\mathrm{r}}=\mathrm{W}_{\mathrm{r}} V^{2} / \mathrm{C}_{\alpha \mathrm{r}} \mathrm{gR} \text { for the rear wheels }
\end{aligned}
$$

The characteristic speed is simply the speed at which the steer angle of the vehicle required to negotiate any turn is equal to twice the Ackerman angle.

$$
\mathrm{K} a_{\mathrm{y}}=57.3 \mathrm{~L} / \mathrm{R}
$$

Since $a_{\mathrm{y}}$ is the function of speed squared, the characteristic speed is given by

$$
V_{\text {char }}=\sqrt{ } 57.3 \mathrm{Lg} / \mathrm{K}
$$

In the oversteer case, a critical speed will exist above which the vehicle will become unstable. The critical speed is given by

$$
V_{\text {crit }}=\sqrt{ } 57.3 \mathrm{Lg} / \mathrm{K}
$$

where $\mathrm{K}$ is negative in value such that the expression under square is positive and has a real value.

\subsection{Simulation using MATLAB-SIMULINK}

By applying the values of the parameters in the high speed cornering formula, the value for the steer angle during 
high speeds can be determined, provided the input parameters such as vehicle speed and radius of turn are known.

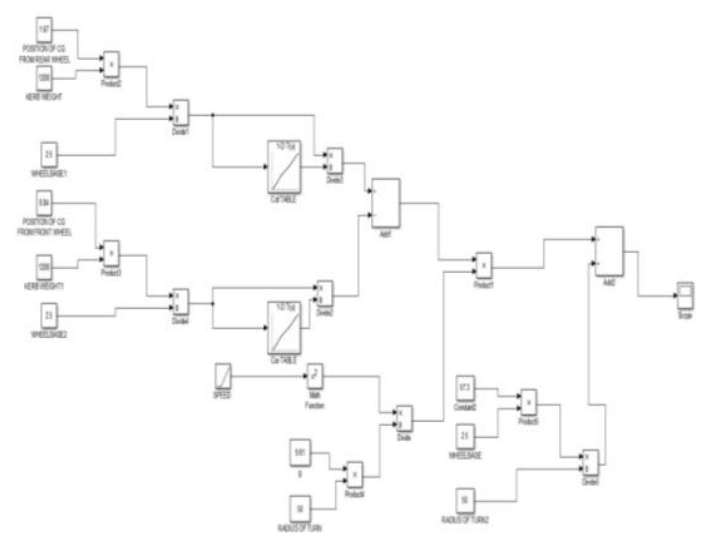

Fig 4.1. Simulink model for a a passenger car

The figure shown above represents the simulink model for a car which is cornering along a curved path. The assumed values as mentioned above are entered in the blocks and the model follows the formula of the high speed cornering in order to determine the steer angle of the vehicle. The scope is the sink block and by clicking on it the graph representing the solution for the model will be displayed. Some of the mathematical blocks such as addition, product, divide, etc are used in this model.

In this method, open the simulink window and start building the model with the help of the various blocks available in the window. In this project, a simulink model is built for a passenger car undergoing cornering at high speed. In this model, take three values for $\mathrm{K}$ - a positive value, a negative value and a zero value. This model is then simulated and the results are noted.

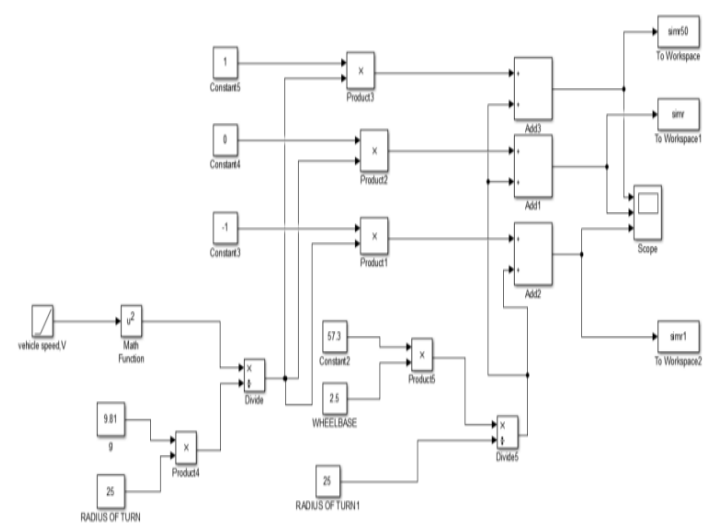

Fig 4.2. Simulimk model for cornering of a car at $K=1,0,1$

The figure above shows the simulink model for the high speed cornering which consists of blocks which are logically connected in order to simulate the results. Here, the values for $\mathrm{K}$ is taken as 1 for simulating the understeer condition, $\mathrm{K}=0$ for simulating the neutral steer condition and $\mathrm{K}=-1$ for simulating the oversteer condition. Then the graph for this model is plotted and the Ackerman angle is determined.

\subsection{Simulation using MATLAB App Designer}

The MATLAB App Designer is a development environment which provides layout and code views along with a fully integrated version of the MATLAB editor and a variety of interactive components. To quickly design the look and feel of the app, simply drag and drop UI components into the app canvas. Build the app with classic components such as buttons, check boxes, and text boxes or replicate the look and feel of an instrument panel with modern components such as knobs, dials, and lamps. And the results can be displayed using one of MATLAB's many $2 \mathrm{D}$ and $3 \mathrm{D}$ plot types. Add more and more functionality, organize the app's components into panels and tab groups.

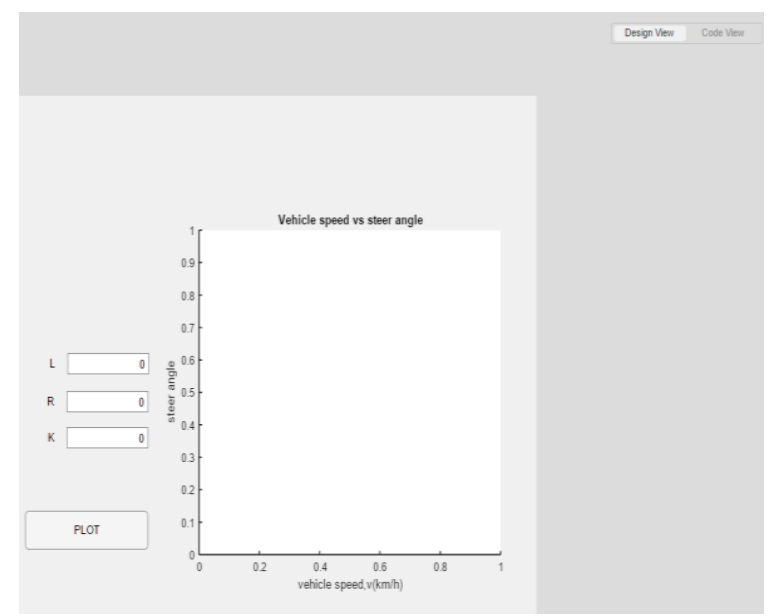

Fig 4.3. Design view of app designer

As the app is designed, App Designer automatically generates all the code that's needed to lay out the app's components. Switch over from Design View to Code View to see all the object-oriented code that has been created and property names that describe the components. With this structure, the UI components are easily accessed and controlled with intuitive dot notation.

In the above figure, three text boxes are dragged and dropped each corresponding for the wheelbase (L), radius of turn $(\mathrm{R})$ and understeer gradient $(\mathrm{K})$ respectively. A push button is used in order to plot the graph for the given input parameters. An axis is also used in order to display the results in the 2-D graph.

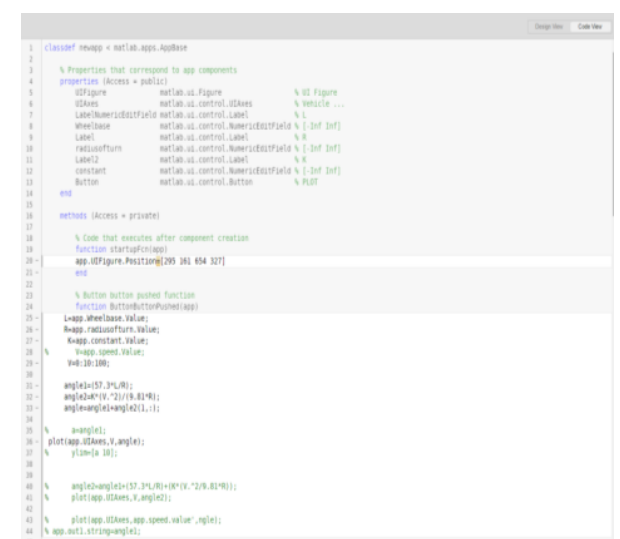

Fig 4.4. Code view of app designer 


\section{MODELLING AND SIMULATION OF SKID PREDICTION IN A PASSENGER CAR}

The above figure shows the code view of the app designer where all the codes required to buid the app is written. In this project, the input parameters entered in the code are wheelbase (L), radius of turn (R) and understeer gradient (K) as shown in the figure. The value of speed of the vehicle $(\mathrm{V})$ is given as a range of values from 0 to $100 \mathrm{~km} / \mathrm{h}$ at an interval of $10 \mathrm{~km} / \mathrm{h}$ which is taken as the $\mathrm{X}$-axis.

Then the formula for the high speed cornering is entered as shown in the figure. The value of the steer angle will be stored in the term 'angle' which calculates the steer angle of the vehicle. The plot command is used in order to plot the speed of the vehicle $(\mathrm{V})$ in th $\mathrm{X}$-axis and steer angle $(\delta)$ in the Y-axis. Then click the run button.

As soon as the run button is pressed, the components in the design view appears in a new window called UI figure which displays the results. In this window, enter the values of the input parameters i.e L, R and $\mathrm{K}$ in the corresponding text boxes and click the plot button. The results will be plotted in the form of 2-D graph.

\section{REAL TIME SIMULATION}

\subsection{Using IPG Carmaker}

IPG Carmaker is asoftware from IPG automotive which consists of model environments such as the intelligent road model, models for roads and traffic, etc. In this project a virtual test driving scenario is created in order to test the whole vehicle in a realistic environment. In order to create a road segment, go to Parameters $>$ road $>$ segment $>$ New or go to Simulation> Scenario Editor. In this project, a curve road having a radius $\mathrm{R}$ is created. Then a driving scenario is created by selecting Parameters> Manouvre in which the speed input is given to the vehicle with respect to the time.

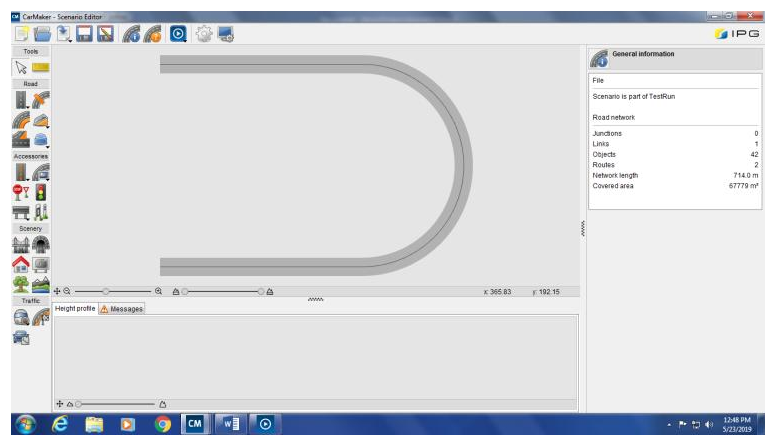

Fig 5.1. Scenario Editor module

The output for the given scenario may be displayed by means of IPG movie, IPG instrument or IPG control. The real time driving environment is created with a passenger car which is undergoing cornering over a curved path as shown below.

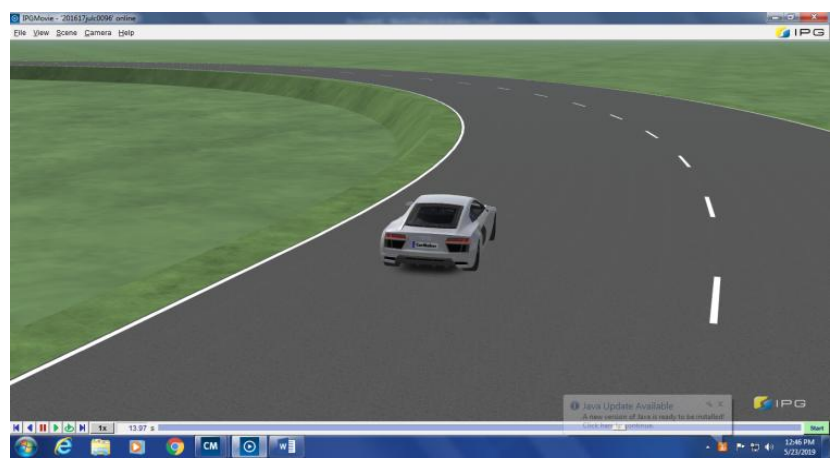

Fig 5.2. Car moving along the road (neutral steer)

When the car is travelling with the suitable combination of speed and steer angle, then the car continues to move along the road. Otherwise, the car goes off the road and skid occurs. So the plot between the speed and the steer angle should be obtained.

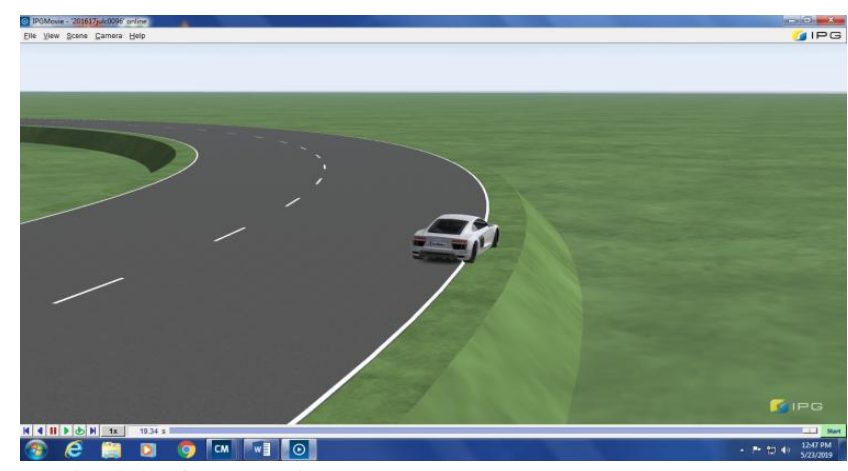

Fig 5.3. Car leaving the road outwards (understeer)

\subsection{Using Driving Scenario Designer app}

Driving Scenario Designer is an app available in MATLAB which is used to design various driving scenarios of the vehicle in real time environment. In this project a virtual test driving scenario is designed in order to test the whole vehicle in a realistic environment for cornering of a car. In order to create a road segment in this app, click on the Add road icon from the Scenario tab. Then draw the desired road segment on the canvas. To simulate the vehicle, click on the Add actors icon from the scenario tab. Specify the name, road width, number of lanes, banking angle, etc as shown below.

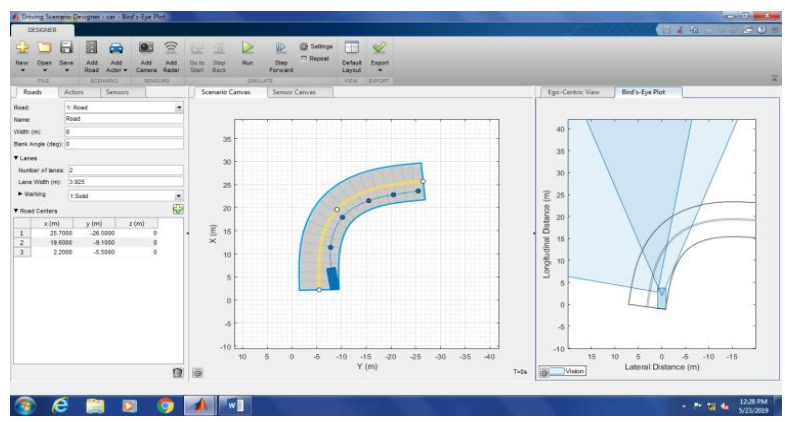

Fig 5.3. Specifying values in roads tab 
Then specify the actor name, length, width, height, etc in the actor tab. The lane in which the actor should travel should also be specified. A manoeuvre is created in which the speed input is given to the vehicle with respect to time.

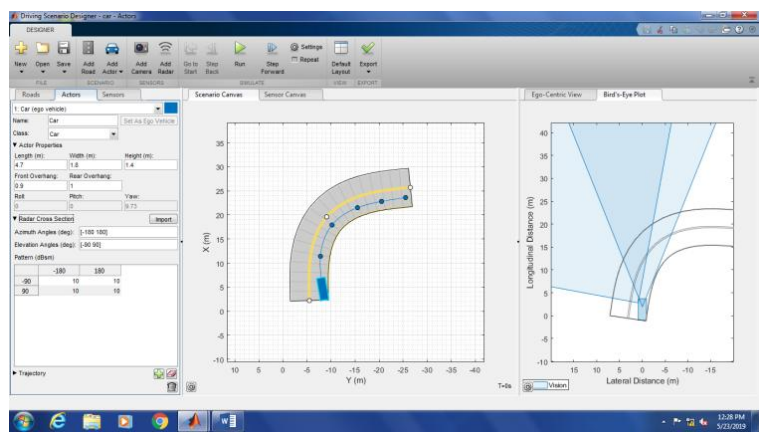

Fig 5.4. Specifying values in actors tab

There is a provision in this app to add vision camera, various sensors, radars, etc to the vehicle so that the desired value can be measured. The output for this scenario can be obtained by clicking run icon. It can be exported to MATLAB script by clicking export icon.

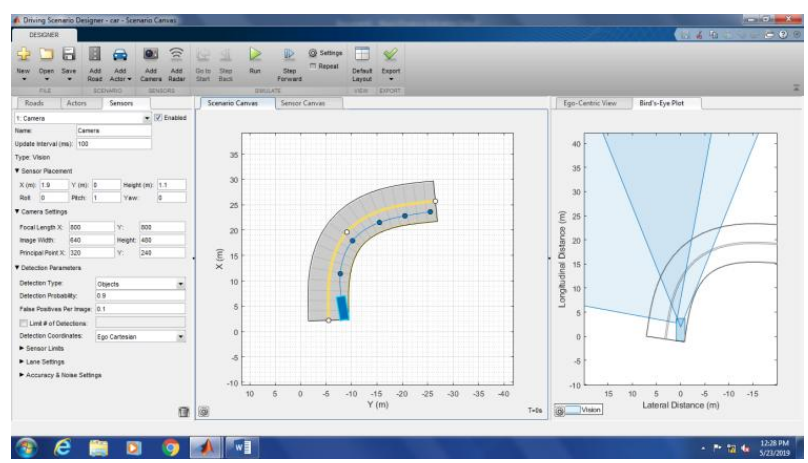

\section{RESULTS AND DISCUSSION}

By running the simulation for the model of the car undergoing cornering by the above mentioned methods for various radius of turn and constant $\mathrm{K}$ value, the following graphs are obtained.

\subsection{Vehicle speed $(V)$ Vs Steer angle $(\delta)$ :}

\subsubsection{For $25 m$ radius of turn:}

Let $\mathrm{K}=1,0,-1, \mathrm{~L}=2.5 \mathrm{~m}$

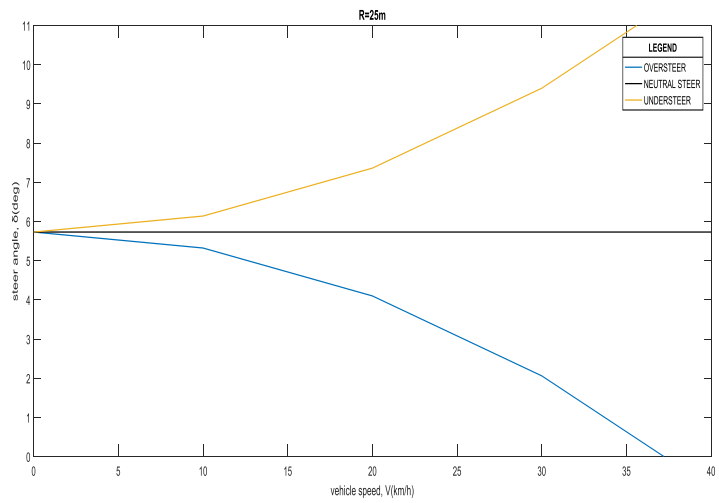

Fig.No.6.1. For 25m Radius of turn

Ackerman angle $=57.3 * \mathrm{~L} / \mathrm{R}$

$=57.3 * 2.5 / 25$

$=5.73 \mathrm{deg}$
Fig 5.5. Specifying values in sensors tab

\subsubsection{For $50 m$ Radius of turn:}

Let $\mathrm{K}=1,0,-1, \mathrm{~L}=2.5 \mathrm{~m}$

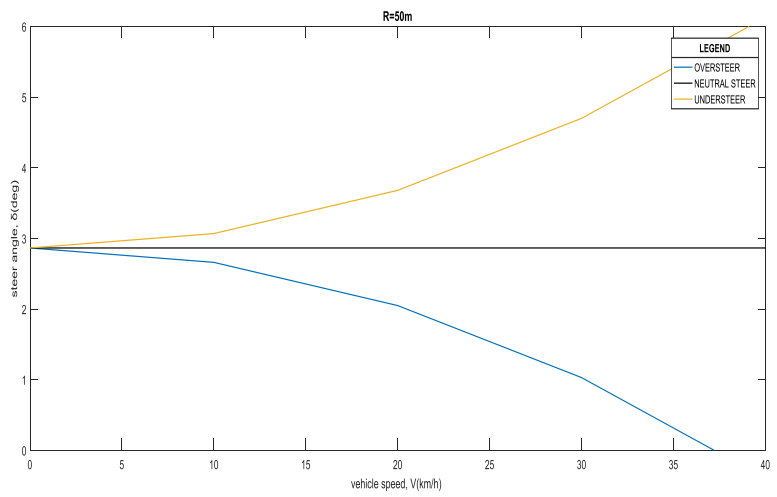

Fig.No.6.2. For $50 \mathrm{~m}$ radius of turn Ackerman angle $=57.3 * \mathrm{~L} / \mathrm{R}$ $=57.3 * 2.5 / 50$ $=2.865 \mathrm{deg}$

6.1.3. For $75 m$ radius of turn:

Let $\mathrm{K}=1,0,-1, \mathrm{~L}=2.5 \mathrm{~m}$

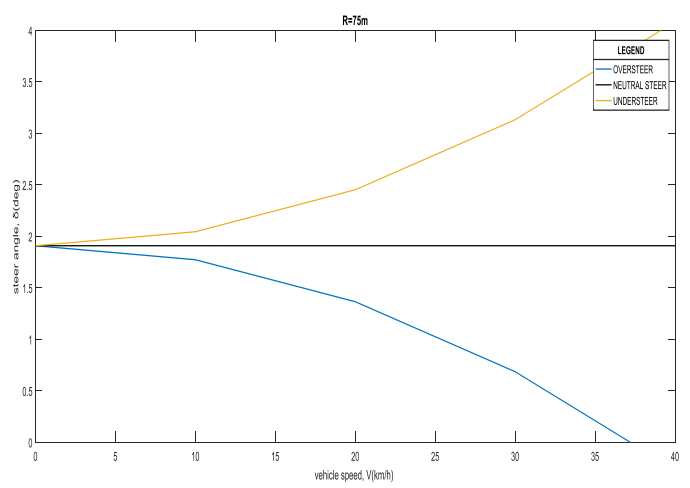

Fig.No.6.3. For $50 \mathrm{~m}$ radius of turn Ackerman angle $=57.3 * \mathrm{~L} / \mathrm{R}$ $=57.3 * 2.5 / 75$ $=1.91 \mathrm{deg}$

\subsubsection{For $100 m$ radius of turn:}

Let $\mathrm{K}=1,0,-1, \mathrm{~L}=2.5 \mathrm{~m}$

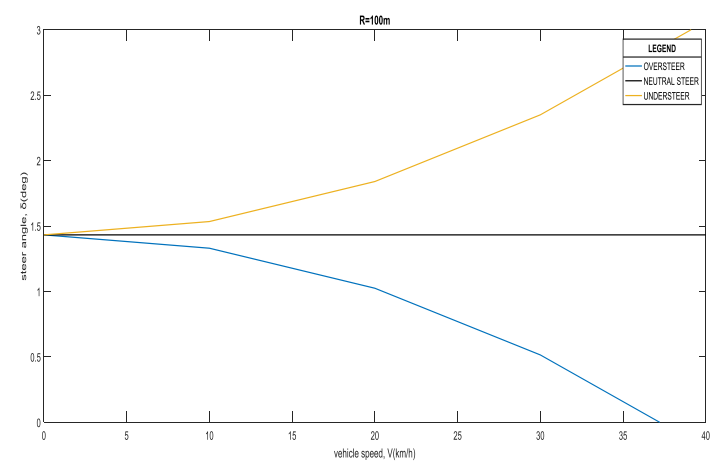

Fig.No.6.4. For $100 \mathrm{~m}$ radius of turn Ackerman angle $=57.3 * \mathrm{~L} / \mathrm{R}$ $=57.3 * 2.5 / 100$ $=1.4325 \mathrm{deg}$

Published By: 


\section{MODELLING AND SIMULATION OF SKID PREDICTION IN A PASSENGER CAR}

\section{CONCLUSION}

In this project, a mathematical model for a car undergoing cornering was done by two methods - one by using equation and the other without using equation. Under the first method where equation is used, the modelling and simulation was done by MATLAB-SIMULINK and MATLAB app designer. Under the second method where equation is not used, the modelling and simulation was done by using IPG Carmaker and Driving Scenario Designer app. In the first method, the equation used for calculating the steer angle of the vehicle is the high speed cornering equation. In the second method without using equation, the real time simulation of the actual environment was created using IPG Carmaker and Driving Scenario Designer app. By running these models, we can simulate and predict the type of skidunder steer, neutral steer or over steer with help of the input parameters like vehicle wheelbase, radius of turn, weight of the vehicle, load acting on the front and the rear axles, position of centre of gravity, etc. The vehicle speed vs steer angle graphs for different radius of turns were obtained and the values of the Ackerman angle were calculated.

\section{REFERENCES}

1. Thomas D. Gillespie(1992). Fundamental of Vehicle Dynamics. Warrendale:SAE.

2. Reza N. Jazar(2014).Vehicle Dynamics -Theory and Application. New York:Springer.

3. An, F. \& DeCicco, J. (2007). Trends in technical efficiency trade-offs for the US light vehicle fleet, SAE Technical Paper, 1325-1341.

4. CarMaker, I. P. G. (2014). Reference manual version 5.0.2. IPG AutomotiveKarlsruhe Germany, 547

5. Zhihua Qu(2009).Cooperative Control of Dynamical Systems. New York:Springer.

6. Allen, R. W., Klyde, D. H., Rosenthal, T. J. \& Smith, D. M. (2003). Estimation of passenger vehicle inertial properties and their effect on stability and handling. Journal of Passenger Cars-Mechanical Systems, 12, 112-132.

7. Blundell M., Harty, D., (2004)Multibody System approach to Vehicle dynamics, SAE.

8. De Bruyne, S., Van der Auweraer, H., Diglio, P. \& Anthonis, J. (2011). Online estimation of vehicle inertial parameters for improving chassis control systems. In Proc. IFAC World Congr, 1814-1819.

9. A. Hac and M. Bodie, "Improvements in vehicle handling through integrated control of chassis systems," International Journal of Vehicle Design, vol. 29, no. 1.

10. Delaigue, P. \& Eskandarian, A. (2004). A comprehensive vehicle braking model for predictions of stopping distances. Proceedings of the Institution of Mechanical Engineers, Part D: Journal of Automobile Engineering, 218(12), 1409-1417.

11. M. Abdulrahim(2006) "On the dynamics of automobile drifting," in SAE World Congress, Detroit, MI,

12. J. Edelmann and M. Plochl(2009)"Handling characteristics and stability of the steady-state powerslide motion of an automobile," Regular and Chaotic Dynamics

13. Fenton, J. (1996). Handbook of vehicle design analysis. England: Mechanical Engineering Publications Limited, 336337 Gong, T., Yan, H. \& Liu, P. F. (2014). Modeling and Simulation for Anti-Lock Braking System (ABS) of Automobiles Based on Simulink. Applied Mechanics and Materials, 716, 1504-1507.

14. Fontaras, G., Pistikopoulos, P. \& Samaras, Z. (2008). Experimental evaluation of hybrid vehicle fuel economy and pollutant emissions over real-world simulation driving cycles. Atmospheric environment, 42(18), 4023-4035.
15. Fukuo, K., Fujimura, A., Saito, M., Tsunoda, K. \& Takiguchi, S. (2001). Development of the ultra-low-fuel-consumption hybrid car-INSIGHT. JSAE review, 22(1), 95-103.

16. Rajeshkumar, S., Balasubramaniam, N., Bhavanakumar, R., Thirumalini, S., (2013). Steering Kickback Diminution on EHPS for Enhancing Vehicle Ride Comfort and Handling. SAE International, (2893).

17. Srinivaas Ashok Kumar et al., (2018). Simulation Study on Variants of ABS. International Journal of Engineering \& Technology, 7 (3.6) (2018) 97-100. 